\title{
Evaluation of care and treatment clinics using a four- year retrospective cohort of patients receiving anti- retroviral therapy in Mbeya Region, Tanzania
}

\author{
Aifello W. Sichalwe ${ }^{1,2 \star}$, J. Renju ${ }^{1,4}$, \\ J. Todd ${ }^{1,4,6}$ \\ G. W. Rutherford ${ }^{8}$, J. Nondi ${ }^{1,3}$, \\ ${ }^{1}$ Kilimanjaro Christian Medical College, Tumaini University, Moshi, Tanzania. \\ ${ }^{2}$ Chunya District Council, Mbeya, Tanzania. \\ ${ }^{3}$ Epidemiology Unit, National AIDS Control Programme, Dar-es-Salaam, Tanzania. \\ ${ }^{4}$ Population Studies Department, London School and Hygiene and Tropical Medicine, London, UK. \\ ${ }^{5}$ Morogoro Regional Hospital, Morogoro, Tanzania. \\ ${ }^{6}$ TAZAMA Project, National Institute for Medical Research, Mwanza, Tanzania. \\ ${ }^{7}$ National Institute for Medical Research (NIMR), Tanga, Tanzania. \\ ${ }^{8}$ University of California, San Francisco, United States of America.
}

E. M. Martin ${ }^{1,5}$

F. Tenu ${ }^{7}$ and

Accepted 30 January, 2018

\begin{abstract}
Evaluations of sub-national anti-retroviral therapy (ART) programmes' performance are important to support regional programme planning and epidemic response. We constructed a four-year retrospective cohort of clients from 10 care and treatment clinics (CTC) in the Mbeya region of Tanzania using routinely collected data from patients initiating ART between January 1, 2008 and March 31, 2012. Our primary outcomes were mortality rate and lost to follow up. We calculated ART coverage based on regional prevalence estimates and used medical cards, drug registers and quarterly reports to assess data quality. We enrolled 17,813 participants into the cohort. More patients initiated ART at WHO stages $3(58.9 \%)$, and at CD4 cell counts between 50-199 cells/ $\mu \mathrm{l}$ (56\%). The proportion of patients initiating ARTs at a CD4 counts $<50$ cells $/ \mu \mathrm{l}$ decreased from $40.7 \%$ in 2008 to $33.8 \%$ in 2012 ( $p$-value $<0.001$ ). A total of $10,155(57.0 \%$ ) patients were lost to follow up (LTFU) during the 4 years of follow up; $59.2 \%$ were female. The overall mortality rate was 17.8 per 1000 person years; the six-month mortality was 6.2 per 1000 person years. The risk of mortality for patients at WHO stage III and IV was more than twice as high (hazard ratio [HR] 2.15; 95\% confidence interval [Cl], 1.05-4.39 and HR 2.29; $95 \% \mathrm{Cl}, 1.39-6.37$, respectively) as compared to stage I and II. Those patients initiating ART with CD4 cell count between 50 and $199 \mathrm{cells} / \mu \mathrm{l}$ had significantly lower hazard of death compared to those initiating ART with CD4 cells counts $<50$ cells $/ \mu \mathrm{l}(\mathrm{HR} 0.51,95 \% \mathrm{Cl} 0.34-0.78)$. In conclusion, during the study, a high proportion of patients were lost to follow up, and the majority of them were female. Most patients initiated ARTs at lower CD4 count $\left(<200\right.$ cells $\left./ \mathrm{mm}^{3}\right)$ and at WHO stages III and IV, and they had higher risk of mortality compared to those initiated at higher CD4 counts and WHO stage I and II. Emphasis needs to be placed on strategies of early diagnosis of HIV infection, prompt initiation of ART, and support for ART adherence to minimise lost to follow up.
\end{abstract}

Keywords: HIV, antiretroviral therapy, Tanzania.

*Corresponding author. E-mail: chifurumakb@yahoo.co.uk.

\section{INTRODUCTION}

Access to anti-retroviral therapy (ART) is rapidly expanding; at the end of 2010 an estimated 6.6 million people were receiving ART in low-income and middleincome countries (Gray et al., 2011). There is increasing 
pressure on national care and treatment programmes to diagnose, enrol and retain large numbers of people onto ART. Increasing coverage requires scaling up programmes across countries and decentralising the provision of care and treatment to lower level facilities. These sites, however, have limited capacity and resources, which may impact their effectiveness. Further, such programmes face considerable challenges caused by patients' late presentation at treatment sites and high levels of attrition (Agu et al., 2010).

The National HIV/AIDS Care and Treatment Plan for the Tanzanian mainland were launched in October 2003, and the actual implementation began in October 2004. Provision of ART was decentralised to regional and district hospitals in 2005 and to health centres starting in 2007. By the end of 2009, Tanzania had approved 909 facilities to provide care and treatment services, enabling more than 300000 patients to access ART (NACP, 2010).

Although Tanzania's national HIV prevalence is $5.6 \%$, there are considerable regional disparities, with a HIV prevalence of $15.7 \%$ in Iringa Region and $9.2 \%$ in Mbeya Region (NACP, 2010). Care and treatment clinics (CTC) have been set up across the country, but there are regional differences in coverage, capacity and resources. The CTCs routinely collect data covering sociodemographic and clinical characteristics and send reports to the National Care and Treatment database. Some clinics report at the individual level and others aggregate the data and report at the clinic level. Few studies have evaluated the CTC programmes based on their collection of routine data, and those that have focus on the national level (Somi et al., 2012). In this paper we present the results from a detailed evaluation of the routinely collected ART programme data from 10 public-sector CTCs using an electronic database in the Mbeya region in the Southern Highlands region of Tanzania.

\section{MATERIALS AND METHODS}

\section{Study design}

We conducted a four-year retrospective cohort analysis to evaluate the CTC programme in Mbeya from January 1, 2008 to March 31, 2012. We supplemented this with a small cross sectional study to review the quality and completeness of data collection at the CTCs and interpretation of national data to make region-specific estimates for the programme coverage.

\section{Study setting}

Mbeya is a highland region located in south-western Tanzania and borders Zambia and Malawi. It has a population of over 2 million people (Commission THEP, nd). Mbeya Region has the third highest prevalence in the country at $9.2 \%$. It has 15 hospitals, 29 health centres and 271 dispensaries. They are 49 CTCs in the region; 10 of these sites had active electronic databases and collected longitudinal data on all patients registered at the CTC since 2006. Patient-level data from these 10 clinics formed the basis of this analysis. According to the 2007 national guidelines, patients were considered eligible for ART if they had WHO stage IV disease irrespective of CD4 cell count, WHO stage III with CD4 $\leq$ 350 cells $/ \mu$ or had CD4 $\leq 200$ cells/ $\mu$ regardless of clinical stage (Somi et al., 2011).

\section{Study population}

We included data for all patients $\geq 15$ years old at the time of ART initiation who began ART at one of the 10 CTCs in Mbeya region from January 2008 to March 2013.

\section{Data collection}

We extracted data from the database to obtain estimates of the regional HIV prevalence stratified by age group. We calculated HIV care coverage by dividing the number of adults currently in care by the estimated total number of HIV-infected adults population at the regional level and ART coverage from the number currently on ART divided by the number in need of treatment. HIV prevalence in adults $\geq 50$ years was estimated as the HIV prevalence in 15-to-49year-old adults divided by the factor of 1.7 (NACP report number 2 , 2010).

We extracted data with the following variables: sociodemographic information, weight, height, CD4 cell count, WHO stage and CD4 count at initiation. For patients' final outcomes we extracted variables for last known status, classified as in care, dead or lost to follow up (which included transferred out, dead, stopped treatment, not attended for the last 3 months).

We used a tool from the Ministry of Health and Social Welfare for the data quality assessment. We randomly sampled five of the 10 clinics with electronic databases to verify data collection, storage and reporting at the service delivery level for data collected between January and June 2012. The tool is a checklist that compiles information pertaining to the number and quality of reports that have been collected and submitted to the national level. The checklist included documentation review, recounting reported results and cross-checking reported results with other data sources. We conducted verification checks between the patient medical dossiers such as standardized form (CTC2 cards) and the relevant registers including ART registers and quarterly reports.

\section{Data analysis}

We analysed the data using Stata version 12 (Stata Corp., College Station, Texas, USA). We used frequencies and percentages to describe categorical variables and median and interquartile ranges (IQR) to describe continuous variables. To investigate baseline predictor changes over time we performed Chi-squared tests for trend and displayed significant results graphically. We calculated unadjusted mortality rates with $95 \%$ confidence limits for each level of predictor variables to explore factors associated with mortality, including socio-demographic characteristics, weight, WHO stage and CD4 count on ART initiation. We fitted unadjusted and adjusted Cox proportional hazard regression models to control potential confounding factors associated with the outcome in crude analysis.

\section{Ethical consideration}

We received permission from the National AIDS Control Programme to use the data and obtained ethical clearance from the Kilimanjaro Christian Medical College research ethics committee. No contact with human subjects occurred. Patients were only identified by number to preserve anonymity; we removed all other 
personal identifiers from the dataset before analysis.

\section{RESULTS}

Overall an estimated 128,285 adults were living with HIV/AIDS in the region at the end of 2011. Of these, $70,327(54.8 \%)$ were enrolled in care and treatment programmes, and 43,084 (33.6\%) were on ART (Figure 1). A total of 17,813 patients had initiated ART in the 10 clinics between January 1, 2008 and March 31, 2012 (Table 1). The medium follow up time was three months IQR (1.0 to 7.3) months, accruing 25,958 person-years observations. Overall, 10,708 (60.1\%) patients were female. The overall age distribution was similar across all years, with an overall median age of 37.0 (IQR 31.0 to 44.0). Functional status at ART initiation improved over time, with more people working (92.8\%), and fewer bedridden (1.3\%). The median baseline weight of patients initiating ART was $52 \mathrm{~kg}$ (range 46.0 to 59); nearly half (46.4\%) weighed between 45 and $55 \mathrm{~kg}$.

Most people initiated ART at WHO stage 3 (58.9\%) and with a CD4 cell count of between 50 and 199 cells $/ \mathrm{mm}^{3}$ (56.0\%). Of the 17,813 that began ART during the study period, $10,155(57.0 \%)$ were lost to follow up during the 4 years of follow up; 5,645 (31.7\%) were lost to follow up within one year. After four years only 7,608 (42.7\%) remained in care. The proportion of patients initiating ART at a CD4 count of $<200$ cells $/ \mu$ fell across the four year cohort (40.7 to $33.8 \%$ ) while the proportion starting ART with a CD4 count of $200-349$ cells/ $/$ l rose in the same period (16.4 to $26.1 \%, \mathrm{p}<0.001$ ) (Figure 2).

Four hundred sixty-two (2.6\%) of 17,813 patients initiating ART were known to have died within the follow up period, with an overall mortality rate of 17.8 per 1000 person years (Table 2). The majority died within the first six month of treatment (6.2 per 1000 person years). Baseline WHO stage, CD4 count, weight, age and gender were predictors of mortality in bivariate analysis. After adjustment all factors except age remained independently and significantly associated with mortality (Table 3). We tested the proportional hazards assumption in the Cox regression model using the test of Schonfield, and there was no evidence against the proportional hazard assumption (global chi-square 21.65 for 16 degree of freedom, $p=0.16$ )

Missing data were common: $21.7 \%$ had missing variables for weight, $24.7 \%$ for functional status, $32.4 \%$ for marital status, $21.7 \%$ for CD4 count, and $98.7 \%$ for body mass index because most height was not documented in $78 \%$. Age and WHO stage had fewer missing data $(0.9 \%$ and $0.4 \%$, respectively).

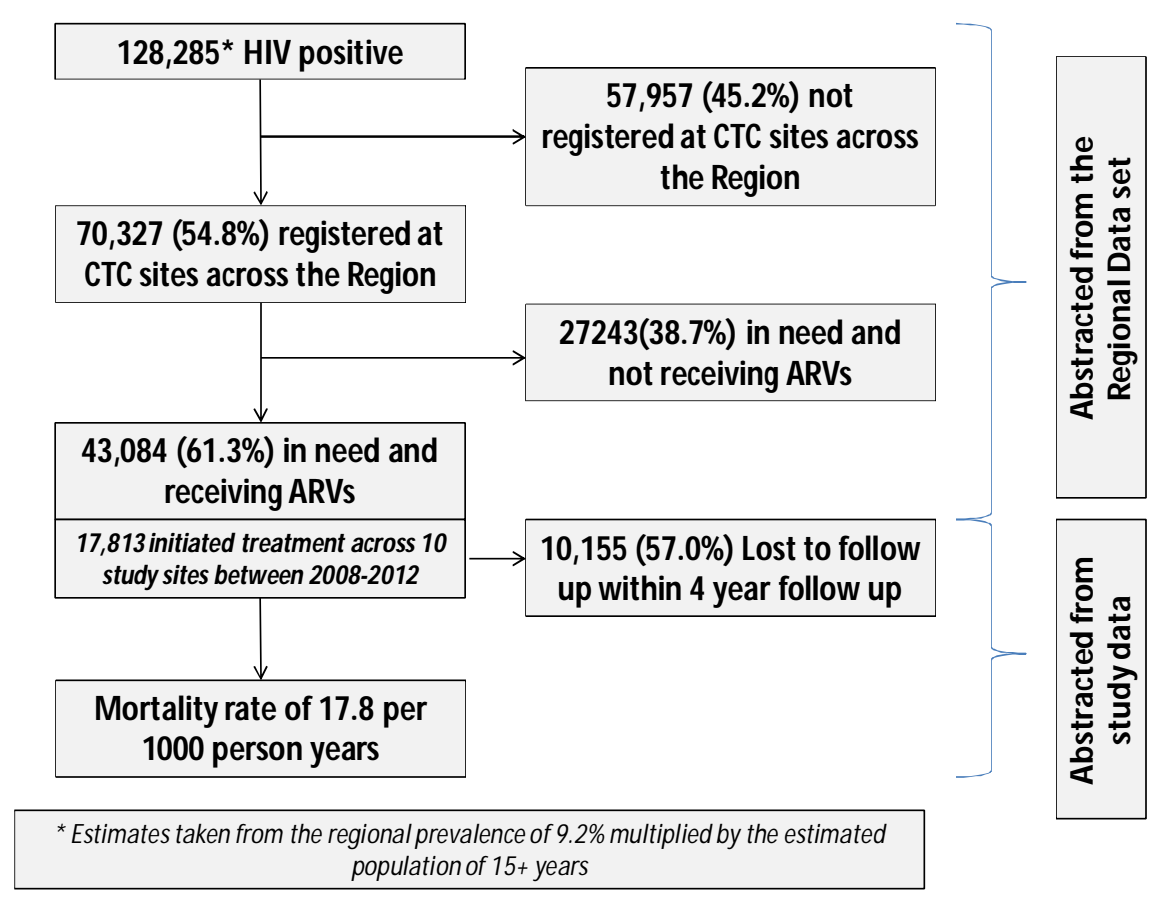

Figure 1. Coverage of HIV services and ART, adults $\geq 15$ years old, Mbeya region, Tanzania, 2011.

\section{DISCUSSION}

We found that after four-years of observation, $57 \%$ of patients who initiated ART in 10 clinics in a highly affected region of Tanzania were lost to follow up and only $42.7 \%$ remained alive and in care. These data were 
Table 1. Baseline and socio-demographic characteristics of the study population.

\begin{tabular}{|c|c|c|c|c|c|c|c|c|c|c|c|c|}
\hline \multirow{2}{*}{$\begin{array}{l}\text { Parameter } \\
\text { Number in study }\end{array}$} & \multicolumn{2}{|c|}{ Total(N) } & \multicolumn{2}{|c|}{2008} & \multicolumn{2}{|c|}{2009} & \multicolumn{2}{|c|}{2010} & \multicolumn{2}{|c|}{2011} & \multicolumn{2}{|c|}{2012} \\
\hline & 17,813 & $\%$ & 4,824 & $\%$ & 4,965 & $\%$ & 3,672 & $\%$ & 3,178 & $\%$ & 1,178 & $\%$ \\
\hline Female & 10,708 & $(60.1)$ & 2,925 & $(60.6)$ & 2,958 & $(59.6)$ & 2,175 & $(59.2)$ & 1,896 & $(59.7)$ & 753 & $(63.9)$ \\
\hline \multicolumn{13}{|l|}{ Age in years } \\
\hline $15-29$ & 3,558 & $(20.2)$ & 969 & $(20.4)$ & 970 & (19.6) & 769 & $(21.1)$ & 628 & $(19.9)$ & 222 & $(18.9)$ \\
\hline $30-39$ & 7,206 & $(40.8)$ & 1,967 & $(41.4)$ & 2,022 & $(40.9)$ & 1,479 & $(40.7)$ & 1289 & $(40.9)$ & 449 & (38.3) \\
\hline $40-49$ & 4,435 & $(25.1)$ & $1,191)$ & $(25.1$ & 1,254 & (25.3) & 865 & $(23.8)$ & 806 & $(25.6)$ & 319 & $(27.9)$ \\
\hline $50+$ & 2,455 & (13.9) & 622 & (13.1) & 695 & $(14.0)$ & 525 & $(14.4)$ & 430 & $(13.6)$ & 183 & $(15.6)$ \\
\hline Missing & 163 & $(0.9 \%)$ & 75 & $(1.6)$ & 24 & $(0.5)$ & 34 & $(0.9)$ & 25 & $(0.8)$ & 5 & $(0.4)$ \\
\hline Median (IQR) & \multicolumn{2}{|c|}{$37.0(31.0-44.0)$} & \multicolumn{2}{|c|}{$36(31-44)$} & \multicolumn{2}{|c|}{$37(31-44)$} & \multicolumn{2}{|c|}{$36(30-44)$} & \multicolumn{2}{|c|}{$37(31-44)$} & \multicolumn{2}{|c|}{$38(31-45)$} \\
\hline \multicolumn{13}{|l|}{ Marital status } \\
\hline Single & 1,940 & $(10.9)$ & 132 & (16.5) & 578 & $(14.6)$ & 562 & $(16.8)$ & 488 & $(17.1)$ & 179 & $(16.7)$ \\
\hline Married/cohabiting & 7,099 & $(39.8)$ & 482 & $(60.4)$ & 2298 & $(57.9)$ & 1917 & $(57.3)$ & 1708 & $(59.8)$ & 695 & $(64.7)$ \\
\hline Divorced/separated & 1,080 & $(6.1)$ & 72 & $(9.02)$ & 373 & $(9.4)$ & 330 & $(9.9)$ & 240 & $(8.4)$ & 66 & $(6.1)$ \\
\hline Widow & 1,928 & $(16.0)$ & 112 & $(14.0)$ & 723 & $(18.2)$ & 537 & $(16.1)$ & 422 & $(14.8)$ & 135 & $(12.6)$ \\
\hline Missing & 5,770 & $(32.4)$ & 4026 & (83.5) & 994 & $(20)$ & 326 & $(8.9)$ & 320 & $(10.1)$ & 104 & $(8.8)$ \\
\hline \multicolumn{13}{|l|}{ Functional status } \\
\hline Ambulatory & 784 & $(5.9)$ & 40 & $(4.8)$ & 129 & $(2.8)$ & 118 & (3.2) & 193 & $(6.1)$ & 304 & $(25.9)$ \\
\hline Bedridden & 177 & $(1.3)$ & 18 & $(2.2)$ & 30 & $(0.7)$ & 80 & $(2.2)$ & 45 & $(1.4)$ & 4 & $(0.3)$ \\
\hline Working & 12,449 & $(92.8)$ & 780 & $(93.1)$ & 4,406 & $(96.5)$ & 3469 & $(94.6)$ & 2927 & $(92.5)$ & 867 & $(73.8)$ \\
\hline Missing & 4,407 & $(24.7)$ & 3,986 & (82.6) & 400 & $(8.1)$ & 5 & $(0.1)$ & 13 & $(0.4)$ & 3 & $(0.3)$ \\
\hline \multicolumn{13}{|l|}{ Weight (kg) } \\
\hline$<45$ & 3,017 & $(17.5)$ & 908 & (19.2) & 887 & $(18.6)$ & 573 & (16.3) & 492 & $(15.9)$ & 157 & $(13.6)$ \\
\hline $45-55$ & 80,006 & $(46.4)$ & 2,301 & $(48.7)$ & 2218 & $(46.4)$ & 1599 & $(45.6)$ & 1343 & (43.3) & 5445 & $(47.3)$ \\
\hline$>56$ & 6,247 & $(36.2)$ & 1,518 & $(32.1)$ & 1673 & $(35.0)$ & 1337 & $(38.1)$ & 1265 & $(40.8)$ & 454 & $(39.3)$ \\
\hline Median (IQR) & \multicolumn{2}{|c|}{$52.0(46.0-59.0)$} & \multicolumn{2}{|c|}{$51.7(46-58)$} & \multicolumn{2}{|c|}{$52(46-59)$} & \multicolumn{2}{|c|}{$53(47-60)$} & \multicolumn{2}{|c|}{$53(47-60)$} & \multicolumn{2}{|c|}{$54(48-60)$} \\
\hline Missing & 547 & $(3.07)$ & 97 & $(2.0)$ & 187 & (3.8) & 163 & $(4.4)$ & 78 & (2.3) & 22 & (1.9) \\
\hline \multicolumn{13}{|l|}{ CD4 Cell count $/ \mu l$} \\
\hline$<50$ & 2,682 & $(19.2)$ & 768 & (20.7) & 779 & (19.7) & 539 & $(19.1)$ & 441 & $(17.7)$ & 155 & $(15.9)$ \\
\hline $50-199$ & 7,812 & $(56.0)$ & 2,249 & $(60.7)$ & 2275 & $(57.4)$ & 1516 & $(53.9)$ & 1240 & $(49.9)$ & 532 & $(54.5)$ \\
\hline $200-349$ & 2,852 & $(20.5)$ & 606 & $(16.4)$ & 750 & $(18.9)$ & 6119 & $(21.9)$ & 648 & $(26.1)$ & 229 & $(23.4)$ \\
\hline $350-499$ & 417 & $(2.9)$ & 58 & $(1.6)$ & 116 & $(2.9)$ & 94 & $(3.3)$ & 104 & $(4.2)$ & 45 & $(4.6)$ \\
\hline$>500$ & 186 & (1.3) & 25 & $(0.7)$ & 41 & $(1.0)$ & 51 & $(1.8)$ & 53 & $(2.1)$ & 16 & $(1.6)$ \\
\hline Missing & \multicolumn{2}{|c|}{$3,868(21.7)$} & 1,118 & $(23.2)$ & 1,004 & $(20.2)$ & 853 & $(23.2)$ & 692 & $(21.8)$ & 201 & $(17.1)$ \\
\hline Median (IQR) cells/ $\mu \mathrm{l}$ & $137(6)$ & $-199.0)$ & $126(6$ & $-185)$ & 133( & 3-194) & 142( & 8-205) & 152 & 3-231) & 148 & 2-212) \\
\hline
\end{tabular}


Table 1. Continues.

\begin{tabular}{|c|c|c|c|c|c|c|c|c|c|c|c|c|}
\hline \multicolumn{13}{|c|}{ WHO stage, number (\%) } \\
\hline 1 & 1,937 & (10.9) & 597 & $(12.4)$ & 493 & $(9.9)$ & 386 & $(10.5)$ & 337 & $(10.7)$ & 124 & (10.6) \\
\hline 2 & 3,117 & $(17.6)$ & 922 & (19.2) & 837 & (16.9) & 600 & (16.4) & 572 & (18.2) & 185 & (15.8) \\
\hline 3 & 10,451 & (58.9) & 2,783 & (57.8) & 2,937 & $(59.4)$ & 1811 & (57.5) & 1811 & (57.5) & 747 & (63.8) \\
\hline 4 & 2,242 & (12.6) & 513 & (10.7) & 677 & (13.7) & 508 & (13.9) & 428 & (13.6) & 116 & $(9.9)$ \\
\hline Missing & 70 & $(0.39)$ & 8 & $(0.2)$ & 21 & $(0.4)$ & 7 & $(0.2)$ & 30 & $(0.9)$ & 4 & $(0.3)$ \\
\hline
\end{tabular}
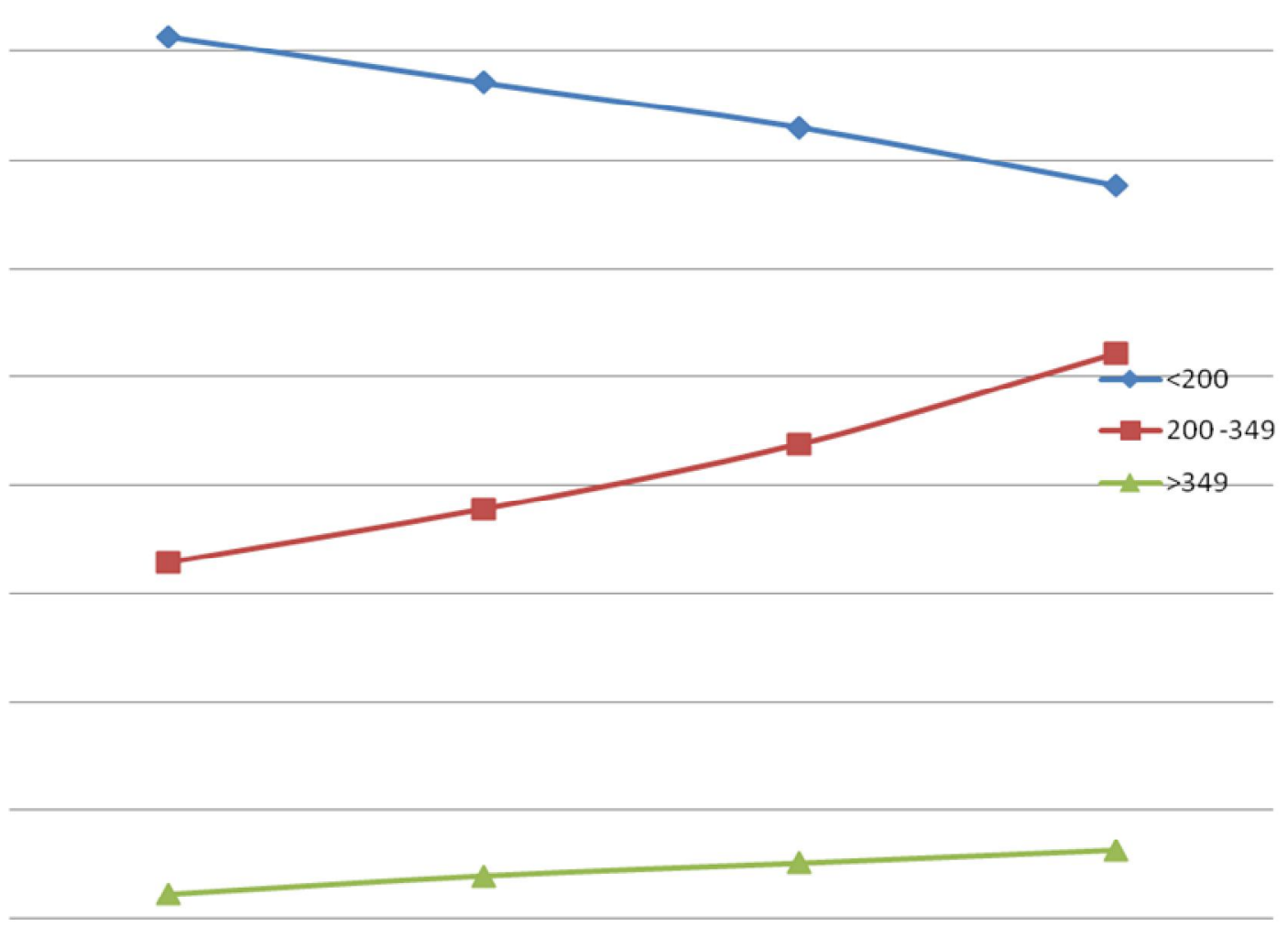

Figure 2.Trend of CD4 cell count across the cohort. Test for trend shows df $12 p$ value $<0.001$. Those initiating ART with CD4 count less than $200 \mathrm{cell} / \mathrm{mm}^{3}$ were decreasing across the cohort, while those initiating ART with CD4 cell $/ \mathrm{mm}^{3}$ were increasing across cohort. However those with $\geq 350 \mathrm{CD} 4 \mathrm{cell} / \mathrm{mm}^{3}$ were slightly increasing with time. 
Table 2. Mortality rates by potential baseline risk factors.

\begin{tabular}{|c|c|c|c|c|c|c|}
\hline Variable & Category & $\begin{array}{c}\text { Number of } \\
\text { people }\end{array}$ & Death & PYAR & $\begin{array}{c}\text { Mortality rates } / 1000 \\
\text { PYAR }(95 \% \mathrm{Cl})\end{array}$ & P value ${ }^{\star \star}$ \\
\hline Overall & & 17,813 & 462 & 25.9 & $17.8(16.2-19.5)$ & \multirow{3}{*}{$<0.001$} \\
\hline \multirow{2}{*}{ Sex } & Male & 7109 & 239 & 10.9 & $23.7(20.9,26.9)$ & \\
\hline & Female & 10708 & 223 & 15.9 & $14.4(12.3,26.9)$ & \\
\hline \multirow{4}{*}{ Age, years } & $15-29$ & 3558 & 89 & 4.91 & $18.1(14.7,22.3)$ & \multirow{4}{*}{0.75} \\
\hline & $30-39$ & 7206 & 189 & 10.50 & $17.9(15.6,20.8)$ & \\
\hline & $40-49$ & 4435 & 106 & 6.64 & $15.9(13.2,19.3)$ & \\
\hline & $50+$ & 2455 & 69 & 3.68 & $18.8(14.8,23.8)$ & \\
\hline \multirow{4}{*}{ Marital status } & Single & 1940 & 59 & 2.18 & $27.1(20.9,34.9)$ & \multirow{4}{*}{0.15} \\
\hline & Married/Cohabiting & 7099 & 190 & 8.65 & $21.9(19.1,25.3)$ & \\
\hline & Divorced/separated & 1080 & 43 & 1.36 & $31.4(23.3,42.4)$ & \\
\hline & Widow & 1928 & 56 & 2.52 & $22.2(17.1,28.9)$ & \\
\hline \multirow{3}{*}{ Functional status } & Ambulatory & 784 & 59 & 0.47 & $79.5(57.6,109.7)$ & \multirow{3}{*}{$<0.001$} \\
\hline & Bedridden & 177 & 190 & 0.21 & $74.8(45.8,122.1)$ & \\
\hline & Working & 12,449 & 43 & 15.89 & $20.0(17.9,22.3)$ & \\
\hline \multirow{3}{*}{ Weight, kg } & $<45$ & 3017 & 111 & 2.16 & $51.3(42.6,61.8)$ & \multirow{3}{*}{$<0.001$} \\
\hline & $45-55$ & 80,006 & 157 & 9.16 & $16.3(16.9,19.1)$ & \\
\hline & $>56$ & 6247 & 111 & 13.42 & $8.3(6.9,9.9)$ & \\
\hline \multirow{5}{*}{ CD4 cell counts, cells $/ \mu \mathrm{l}$} & $<50$ & 2682 & 124 & 3.57 & $34.8(29.1,41.4)$ & \multirow{5}{*}{$<0.001$} \\
\hline & $50-199$ & 7812 & 180 & 11.58 & $15.5(13.4,17.9)$ & \\
\hline & $200-349$ & 2852 & 60 & 3.99 & $15.0(11.7,19.3)$ & \\
\hline & $350-499$ & 417 & 16 & 0.50 & $31.9(19.6,52.2)$ & \\
\hline & $>500$ & 186 & 4 & 0.21 & $19.4(7.3,51.8)$ & \\
\hline \multirow{4}{*}{ WHO stage } & 1 & 1937 & 20 & 3.05 & $6.6(4.2,10.2)$ & \multirow{4}{*}{$<0.001$} \\
\hline & 2 & 3117 & 49 & 4.90 & $9.9(7.6,713.2)$ & \\
\hline & 3 & 10,451 & 298 & 15.14 & $19.7(17.6,22.0)$ & \\
\hline & 4 & 2242 & 94 & 2.78 & $33.8(27.6,41.3)$ & \\
\hline
\end{tabular}

PYAR: person-years at risk; MR: mortality rate; $\mathrm{Cl}$ : confidence interval, ${ }^{* *} \mathrm{p}$ value from log-rank test.

collected before the massive expansion of ART in Tanzania that has accompanied the new WHO guidelines and the 90-90-90 goals. While our data suggest programme performance comparable to that seen during the same period in Papua Guinea and Nigeria (Gray et al., 2011; Onoh, 2010) and while Tanzania has decentralised ART care to lower-level health facilities, which should theoretically improve access, our data suggest significant challenges in diagnosing, initiating and retaining patients on ART. Nonetheless, progress is evident. In Mbeya between 2009 and 2011 there was a $50 \%$ increase in the number of ART-eligible patients who initiated treatment. Our study has also shown that in this region those initiating ART were doing so at an increasingly higher CD4 count as the programme progressed over the fourth-year (NACP, 2010).
Using routine data to evaluate regional programmes is sustainable and realistic. Unlike clinical trials, which are designed to address proof of concept issues, integrating operational research utilising data collected routinely from standard government clinics has the potential to give a real picture of what is happening on the ground. The scale up of the computerised system across the country should make the system more timely and less arduous. However, the considerable amounts of missing data we found in our study support other studies in suggesting that the process needs reviewing and careful monitoring (Somi et al., 2012; Commission THEP, nd; Somi et al., 2011). For instance, in our study it was not possible to calculate or utilise body mass index (an important metric to monitor trends and progress of patients on ART) given that height was consistently omitted in the registers. 
Table 3. Factors associated with mortality.

\begin{tabular}{|c|c|c|c|c|c|c|}
\hline Factor & Level & $\mathbf{N}$ & Mortality rates & $\begin{array}{c}\text { Unadjusted HR * } \\
(95 \% \mathrm{Cl})\end{array}$ & $\begin{array}{c}\text { Adjusted HR * } \\
(95 \% \mathrm{Cl})\end{array}$ & Adjusted $p$ value \\
\hline \multirow{2}{*}{ Sex } & Male & 7109 & 23.7 & Referent & Referent & \\
\hline & Female & 10708 & 14.4 & $0.61(0.51,0.73)$ & $0.47(0.35,0.62)$ & $<0.001$ \\
\hline \multirow{4}{*}{ Age, years } & $15-29$ & 3558 & 18.13 & Referent & Referent & \\
\hline & $30-39$ & 7206 & 15.61 & $1.03(0.79,1.31)$ & $0.9(0.62,1.29)$ & 0.62 \\
\hline & $40-49$ & 4435 & 13.21 & $0.93(0.69,1.23)$ & $0.82(0.59,1.14)$ & 0.241 \\
\hline & $>50$ & 2455 & 14.82 & $1.09(0.79,1.49)$ & $1.01(0.69,1.49)$ & 0.941 \\
\hline \multirow{3}{*}{ Weight, kg } & $<45$ & 3017 & 51.3 & $4.68(3.59,6.1)$ & $5.93(4.23,8.33)$ & $<0.001$ \\
\hline & $45-55$ & 80,006 & 16.3 & $1.77(1.39,2.26)$ & $1.6(1.16,2.21)$ & 0.004 \\
\hline & $>55$ & 6247 & 8.3 & Referent & Referent & \\
\hline \multirow{4}{*}{ WHO stage } & 1 & 1937 & 6.6 & Referent & Referent & \\
\hline & 2 & 3117 & 9.9 & $1.53(0.91,2.58)$ & $1.38(0.61,3.10)$ & 0.441 \\
\hline & 3 & 10,451 & 19.7 & $2.89(1.84,4.54)$ & $2.15(1.05,4.39)$ & 0.036 \\
\hline & 4 & 2242 & 33.8 & $4.50(2.78,7.29)$ & $2.97(1.39,6.37)$ & 0.005 \\
\hline \multirow{5}{*}{ CD4 cell count, cells $/ \mu l$} & $<50$ & 2682 & 34.8 & Referent & Referent & \\
\hline & $50-199$ & 7812 & 15.5 & $0.47(0.38,0.59)$ & $0.75(0.55,1.01)$ & 0.06 \\
\hline & $200-349$ & 2852 & 15.0 & $0.44(0.33,0.60)$ & $0.51(0.34,0.78)$ & 0.002 \\
\hline & $350-499$ & 417 & 31.9 & $0.87(0.52,1.47)$ & $0.49(0.19,1.21)$ & 0.12 \\
\hline & $>500$ & 186 & 19.4 & $0.50(0.19,1.36)$ & $0.51(0.12,2.08)$ & 0.34 \\
\hline
\end{tabular}

${ }^{*}$ Hazard Ratio; $\mathrm{Cl}$ confidence interval.

Our study describes factors associated with mortality in Mbeya, which are comparable to those found in other African programmes (Biadgilign et al., 2012; Lawn et al., 2008; Barth et al., 2011) with the majority of deaths occurring in the first 6 months after ART initiation (Amuron et al., 2011; Stewart et al., 2012; Bussmann et al., 2008). It is generally accepted that any improvements in mortality are likely to come from, amongst other things, more timely ART initiation (Johannessen et al., 2008). Historically, patients in Africa presented for ART once they developed advanced symptomatic disease with dangerously low CD4 counts (Johannessen et al., 2008; Orrell et al., 2011). We found that, whilst this is still often the case, the situation is changing. Data from Mbeya show a significant positive trend from 2008 to 2012 in the starting of ART at increasingly higher CD4 counts. However the median of 137 cells/ $\mu$ l during this period was still far below the then WHO recommended threshold for initiating ART at $<350$ cells/ $\mu \mathrm{l}$ (WHO 2010) and still low for the country which, in 2009, had a median CD4 count at ART initiation of $155 \mathrm{cells} / \mu \mathrm{l}$ (NACP, 2012). The high rates of loss to follow up in this study were seen in many others (Togun et al., 2011; Mossdorf et al., 2011). The challenge involved in minimising loss to follow up is significant given that as the CTC system currently stands it is not possible to track those that no-longer report for treatment.
We recognise that our study has a number of important limitations. First, the patient records were often incomplete, particularly with regard to recording of height, CD4 cell counts, marital status, and functional status; therefore, the association of these variables with mortality may be underestimated. Similarly, some treatment outcomes recorded as 'lost to follow up' are most likely deaths, thereby underestimating mortality in this study. A study of tracing ART patients lost to follow up in South Africa found that $48 \%$ of patients who were recorded as lost to follow up were actually dead, $25 \%$ had relocated to other clinics, $10.5 \%$ were hospitalised and $4.6 \%$ had stopped medication after feeling well (Dalal et al., 2008). Despite these limitations, our study highlights important areas of focus for the monitoring and evaluation of the system. In addition to this further emphasis needs to be placed in Mbeya region and most probably across the country on strategies to increase the timely diagnosis of HIV infection and initiation of ART at higher CD4 counts; this will require expanded HIV testing, further decentralisation of CTC sites and in reducing out of pocket patient costs to facilitate improved access service.

\section{Conclusion}

Poor data quality, documentation and reporting within 
both the computerised and paper-based patient record systems limit the utility of the data for the purpose of programme evaluation and planning. From the data collected we conclude that whilst positive trends exist, further emphasis is needed on strategies to increase the timely initiation of ART at higher CD4 counts and to improve retention in care. We emphasise the need for an improved monitoring system to track those enrolling, initiating and dropping out of the system.

\section{Declaration of conflict of interest}

The authors declare that they have no conflicts of interest.

\section{ACKNOWLEDGEMENTS}

The authors would like to thank the Chunya District Council for funding this work. We also acknowledge the cooperation from Epidemiology Department of Kilimanjaro Christian Medical College, Tumaini University and Epidemiology Unit, National AIDS Control Programme for permission to use data, the University of California, San Francisco, United States of America, for conducting the manuscript writing workshop where we developed this manuscript and all people involved in the workshop. We also thank all the health facilities staff for their cooperation and patients who their data were used in this study.

\section{REFERENCES}

Agu K, Ochei U, Oparah A, Onoh O, 2010. Treatment outcomes in patients receiving combination antiretroviral therapy in Central Hospital, Benin City, Nigeria. Trop J Pharmaceut Res, 9: 1-10.

Amuron B, Levin J, Birunghi J, Namara G, Coutinho A, Grosskurth H, Jaffar S, 2011. Mortality in an antiretroviral therapy programme in Jinja, south-east Uganda: A prospective cohort study. AIDS Res Ther, 8(1): 39.

Barth RE, Tempelman H, Moraba R, Hoepelman AIM, 2011. Long-term outcome of an HIV-treatment programme in rural Africa: Viral suppression despite early mortality. AIDS Res Treatment, 434375.

Biadgilign S, Reda A, Digaffe $T$, 2012. Predictors of mortality among HIV infected patients taking antiretroviral treatment in Ethiopia: A retrospective cohort study. AIDS Res Ther, 9(1): 15.

Bussmann H, Wester CW, Ndwapi N, Grundmann N, Gaolathe T, Puvimanasinghe J, Avalos A, Mine M, Seipone K, Essex M, Degruttola V, Marlink RG, 2008. Five-year outcomes of initial patients treated in Botswana's National Antiretroviral Treatment Program. AIDS, 22(17): 2303-2311.

Commission THEP, Salaam DARES, Office RCS, nd. The United Republic of Tanzania Mbeya Region Socio-Economic Profile. Annual Report.

Dalal RP, Macphail C, Mqhayi M, Wing J, Feldman C, Chersich MF, Venter WD, 2008. Characteristics and outcomes of adult patients lost to follow-up at an antiretroviral treatment clinic in Johannesburg, South Africa. Epidemiol Soc Sci, 47(1): 101-107.

Gray RT, Zhang L, Lupiwa T, Wilson DP, 2011. Forecasting the population-level impact of reductions in HIV antiretroviral therapy in Papua New Guinea. AIDS Res Ther, 1-8.
Johannessen A, Naman E, Ngowi BJ, Sandvik L, Matee MI, Aglen HE, Gundersen SG, Bruun JN, 2008. Predictors of mortality in HIVinfected patients starting antiretroviral therapy in a rural hospital in Tanzania. BMC Infect Dis, 8: 52.

Lawn SD, Harries AD, Anglaret X, Myer L, Wood R, 2008. Early mortality among adults accessing antiretroviral treatment programmes in sub-Saharan Africa. AIDS, 22(15): 1897-1908.

Mossdorf E, Stoeckle M, Mwaigomole EG, Chiweka E, Kibatala PL, Geubbels E, Urassa H, Abdulla S, Elzi L, Tanner M, Furrer H, Hatz C, Battegay M, 2011. Improved antiretroviral treatment outcome in a rural African setting is associated with cART initiation at higher CD4 cell counts and better general health condition. BMC Infect Dis, 11(1): 98.

NACP, 2010. United Republic of Tanzania: Ministry of Health and Social Welfare National AIDS Control Programme Implementation of HIV/AIDS Care and Treatment Services in Tanzania Report Number 2 Abbreviated Edition March 2010. Annual report. 2010;(2).

NACP, 2012. The United Republic of Tanzania National Guidelines. Annual report 2012

Orrell C, Kaplan R, Wood R, Bekker LG, 2011. Virological breakthrough: a risk factor for loss to follow-up in a large communitybased cohort on antiretroviral therapy. AIDS Res Treatment, 469127.

Somi G, Keogh S, Todd J, Kilama B, Wringe A, van den Hombergh J, 2011. Using clinic and survey data to estimate coverage of HIV care and treatment services in Tanzania.

Somi G, Keogh SC, Todd J, Kilama B, Wringe A, van den Hombergh J, Malima K, Josiah R, Urassa M, Swai R, Zaba B, 2012. Low mortality risk but high loss to follow-up among patients in the Tanzanian national HIV care and treatment programme. Trop Med Int Health, 17(4): 497-506.

Stewart A, Chan Carusone S, To K, Schaefer-McDaniel N, Halman M, Grimes R, 2012. Causes of death in HIV patients and the evolution of an AIDS hospice: 1988-2008. AIDS Res Treatment, 390406.

Togun T, Peterson I, Jaffar S, Oko F, Okomo U, Peterson K, Jaye A, 2011. Pre-treatment mortality and loss-to-follow-up in HIV-1, HIV-2 and HIV-1/HIV-2 dually infected patients eligible for antiretroviral therapy in The Gambia, West Africa. AIDS Res Ther, 8(1): 24. Citation: Sichalwe AW, Renju J, Rutherford GW, Nondi J, Martin EM,
Tenu F, Todd J, 2018. Evaluation of care and treatment clinics using a
four-year retrospective cohort of patients receiving anti-retroviral
therapy in M beya Region, Tanzania. Int Res J Med Med Sci, 6(1): 10-
17. 